\title{
Gastrointestinal Stromal Tumor with Dieulafoy Lesion: A Novel Association
}

\author{
Hemender Singh Vats, MD; Timothy J.Wengert, MD; and Camille F.Torbey, MD
}

\section{A} history of black loose stools for the 4 days prior to admission. He felt weak and light-headed and reported chronic symptoms of heartburn, but no history of hematochezia. Rectal examination revealed strongly occult-positive stools. Hemoglobin, at presentation, was $8.6 \mathrm{~g} / \mathrm{dl}$. Same-day esophagogastroduodenoscopy (EGD) revealed a large smooth submucosal tumor situated at the lesser curvature, distally. It measured 4 $\mathrm{cm} \times 4 \mathrm{~cm}$ and was clinically consistent with a gastrointestinal stromal tumor (GIST). Close examination of the lesion revealed a protuberant shiny erythematous blood vessel without any active bleeding (figure 1A). There were no surface ulcers or erosions. Given these characteristics, it was felt we were dealing with a Dieulafoy lesion. We sprayed the lesion with water using a 7 Fr bipolar circumactive probe (BiCAP), which resulted in immediate bleeding (figure 1B). Though difficult, hemostasis was successfully achieved with BiCAP (setting of 4, Valley Lab Force Ez, Boulder, CO) followed by application of 4 clips (QuickClip2, Olympus, Melville, NY), resulting in complete hemostasis and ablation of the Dieulafoy lesion. The patient required 3 units of packed red blood cells. Computerized axial tomographic (CAT) scan of the abdomen showed a heterogeneous, nearly spherical tumor approximately $5 \mathrm{~cm}$ in diameter in the lesser curvature of the stomach. The patient subsequently underwent wedge resection of the tumor. Histopathological examination was consistent with a GIST with less than 5 mitoses per 50 HPF.

Dieulafoy lesion was first identified as a rare cause of gastrointestinal bleeds by Gallard in 1884 and later described by Dieulafoy in 1897. The typical lesion is a lentil-sized round mucosal defect with an artery
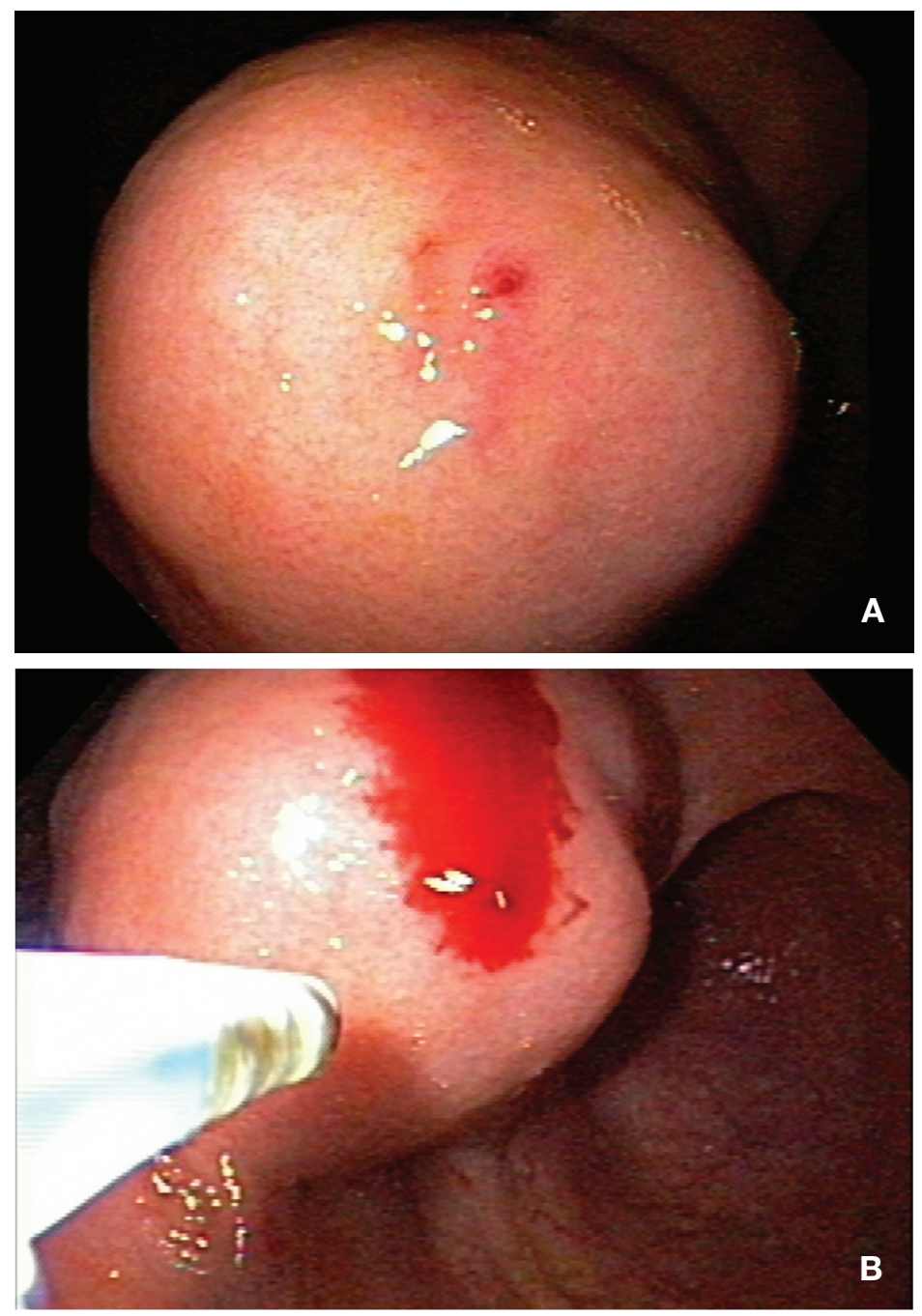

Figure 1. (A) Endoscopic image showing a well-delineated Dieulafoy lesion overlying a large gastrointestinal stromal tumor on the lesser curvature of the stomach. (B) The Dieulafoy lesion demonstrated brisk bleeding with simple irrigation.

Keywords:

Gastrointestinal stromal tumor, Dieulafoy lesion, Esophagogastroduodenoscopy, Computerized axial tomography

Received: July 17, 2006

Accepted: July 27, 2006 
protruding from its base. Such lesions are responsible for $0.3 \%$ to $1.5 \%$ of major gastrointestinal bleeds and most commonly occur in the stomach on the lesser curvature, within $6 \mathrm{~cm}$ of the gastroesophageal junction. Lesions have also been reported in the esophagus, duodenum, ileum and colon. They bleed easily and can cause massive hemorrhage. EGD can readily diagnose most of the gastric lesions. Occasionally, however, they can be elusive, requiring subsequent $\mathrm{EGD}$ for definitive diagnosis and therapy. Diagnosis of Dieulafoy lesions in other sites is difficult and can be attempted by selective angiography. Endoscopic therapy includes epinephrine injection, thermocoagulation, laser photocoagulation, band ligation and hemoclips. Surgical management is reserved for patients who fail endoscopic management. ${ }^{1,2}$

GISTs encompass a heterogeneous group of mesenchymal tumors and constitute approximately $3 \%$ of all soft tissue sarcomas. They are very uncommon, affecting approximately 4/1,000,000 people. Seventy percent of GISTs occur in the stomach with peak incidence in the fifth and sixth decades. Malignant potential is predicted by size $(>5 \mathrm{~cm})$ and mitotic activity $(>10$ mitoses/HPF). GISTs are typically asymptomatic. Bleeding from ulcers in the overlying mucosa is the most common manifestation, followed by obstructive symptoms by virtue of tumor size. Surgical resection is the preferred treatment and complete tumor resection can be accomplished in $50 \%$ to $80 \%$ of cases. $^{3,4}$

This case of massive gastrointestinal bleed from a Dieulafoy lesion overlying a GIST is, to the best of our knowledge, a novel and unique clinical presentation that has not yet been reported in the literature. While this association did not result in a management change, it does underscore the ubiquitous nature of Dieulafoy lesions.

\section{References}

1. Schmulewitz N, Baillie J. Dieulafoy lesions: a review of 6 years of experience at a tertiary referral center. Am J Gastroenterol 2001;96:1688-1694.

2. Gadenstatter M, Wetscher G, Crookes PF, Mason RJ, Schwab G, Pointner R. Dieulafoy's disease of the large and small bowel. J Clin Gastroenterol 1998; 27:169-172.

3. Shinomura Y, Kinoshita K, Tsutsui S, Hirota S. Pathophysiology, diagnosis and treatment of gastrointestinal stromal tumors. J Gastroenterol 2005;40:775-780.

4. Von Mehren M, Watson JC. Gastrointestinal stromal tumors. Hematol Oncol Clin North Am 2005; 19:547-564.

\section{Author Affiliations}

Hemender Singh Vats, MD, Department of Internal Medicine, Marshfield Clinic, 1000 North Oak Avenue, Marshfield, Wisconsin 54449

Timothy J. Wengert, MD, Department of General Surgery, Marshfield Clinic, 1000 North Oak Avenue, Marshfield, Wisconsin 54449

Camille F. Torbey, MD, Department of Gastroenterology, Marshfield Clinic, 1000 North Oak Avenue, Marshfield, Wisconsin 54449

DApart? , like the opening in the lens of a microscope that allows light to pass through, is a forum for art, humor, and images that provides a portal for new or different views of medicine and research. 